\title{
Additive fuzzy multiple goal programming model for unbalanced multi- objective transportation problem
}

\author{
Lohgaonkar M.H. ${ }^{1}$, Bajaj V.H. ${ }^{1 *}$ and Jadhav V.A. ${ }^{2}$ \\ ${ }^{\star} 1$ Department of Statistics, Dr. B. A. M. University, Aurangabad, MS, vhbajaj@gmail.com, \\ mhlohgaonkar@gmail.com \\ ${ }^{2}$ Departments of Statistics, Science College, Nanded, MS
}

\begin{abstract}
This paper introduces fuzzy goal programming approach to unbalanced transportation problem with additive multiple fuzzy goals, when the goals are considered to be of equal importance. But in reality all goals may not be of equal importance. Here we have discussed two different ways of assigning weights to additional model described in the paper. The direct weights are used in fuzzy goal programming model for unbalanced multi-objective transportation problem.
\end{abstract}

Keyword- Additive fuzzy method, goal programming, multiple fuzzy goals, unbalanced transportation problem

\section{Introduction}

Goal programming (GP) is a suitable method to solve Multicriteria Decision Making (MCDM) problems with multiple conflicting objectives. The detailed analysis of GP has been given by Lee [9], Ignizio [5, 6, 7], and Romero [12]. Goal Programming is being used in multicriteria decision making problems where the alternatives cannot be compared on the basis of a single performance criterion. In goal formulation, the aspiration level is fixed and the decision maker has no control over the deviation from the aspiration level. To overcome these difficulties, we have investigated Fuzzy Goal Programming (FGP) of an unbalanced transportation problem with multiple fuzzy goals where all the goals are equally important. To reflect the equal importance of the goals, equal weights are assigned to them. In most of the MCDM problems in the real world, the articulation of the goals and objectives of the decision maker are fuzzy in nature. Bellman and Zadeh [1] dealt with the problems involving decision making under fuzzy environment. The application of the fuzzy set theory to GP has been made by Narasimhan [11] and Hannan [3]. Tiwari et al. [14] have investigated how the preemptive priority structure can be used in FGP problems. Tiwari et al. [15] have developed an additive model for fuzzy goal programming problems. This paper shows FGP models can be formulated for multiobjective unbalanced transportation problems by using the basic notions of fuzzy subsets and those problems can be solved by linear programming methods. The max-min operator has been used to aggregate the fuzzy goals since this operator treats all the goals as equally important. In many instances, the decision maker finds multiple conflicting objectives in a transportation problem. In such cases, the usual transportation method cannot be used. It is possible to apply the GP approach to such transportation problems. Lee and Moore [10] have shown the application of goal programming to multiobjective transportation problem. Kwak [8] considered a GP model for improved transportation problem. Weighted goal programming for unbalanced single objective transportation problem with budgetary constraint has been discussed by Singh and Kishore [13]. Bit et al [2] have presented a transportation problem model for the allocation of coal and its by products (soft coke, middling, and washed coal) from different sources and converting plants of coal mines to different consumption sites. The model has been formulated to meet the energy demand, and to minimize the transportation problem cost. A case study is presented and the problem is solved using goal-programming method in order to find a satisfactory solution. In many decision-making situations, the decision maker faces an unbalanced transportation problem in which total supply is less than the total demand. Due to the scarcity of funds, the decision maker is not able to satisfy all the demand points fully with the existing availability. In such cases the solution is affected by the multiple objectives. This type of problem is faced by the government agencies like Food Corporation of India, $(\mathrm{FCl})$ which supplies food grains from different warehouses (i.e., source points) to different distribution centers (i.e., demand points). Although the quantity of food grains supplied is not sufficient to meet the demand of each distribution center. It is not possible for the $\mathrm{FCl}$ to transport even the available capacity due to paucity of fund. It is very difficult to supply food grains even to all remote places where multiple objective values are very high due to lack of approachability to such places. But it is essential to supply a certain percentage of the demand to save the people from starvation.

\section{Unbalanced Transportation Problem with Multiple Fuzzy Goals}

In a typical transportation problem, a homogeneous product is to be transported from each of $m$ sources to $n$ destinations. The sources 
are production facilities, warehouses, or supply point, characterized by available capacities $a_{i}(i=$ $1,2, \ldots, m)$. The destinations are consumption facilities, warehouses, or demand points, characterized by required levels of demand $b_{j}(j$ $=1,2, \ldots, n)$. A penalty $C^{p_{i j}}$ is associated with transportation of a unit of the product from sources $i$ to destination $j$ corresponding to the $p$ th criterion. The penalty could represent transportation cost, delivery time, deterioration of total goods, quantity of goods delivered, under used capacity, etc. A variable $X_{i j}$ represents the unknown quantity to be transported from origin $\mathrm{O}_{i}$ to destination $D_{j}$. In the real would, however, multi-objective transportation problems are not balanced and objectives are not precisely specified (i.e., goals are fuzzy in nature). We have formulated the FGP model of an unbalanced multiobjective transportation problem in which the objectives and demands are specified imprecisely. The decision variables, supply constrain, fuzzy demand goals and fuzzy multiple goal are identified as follows:

- Decision variable:

Decision variables for the model are defined as

$$
\begin{aligned}
& x_{i j}, \quad i=1,2, \ldots, m ; j=1,2, \ldots, n \\
& \sum_{i=1}^{m} x_{i j} \underset{\%}{\geq} b_{j}, j=1,2, \ldots, n \\
& \text { where } b_{j}>0 \text { for all } j \text {. }
\end{aligned}
$$$$
\text { where } x_{i j} \geq 0 \text { for all } i \text { and } j
$$

- System or supply constraints:

The symbol $\geq_{n}$ stands for approximately or nearly greater than or equal to.

- Multiple fuzzy goals:

$Z_{p}=\sum_{i=1}^{m} \sum_{j=1}^{n} c_{i j}^{p} x_{i j} \underset{\%}{\infty} B^{p}, \quad p=1,2, \ldots, P$

Where the superscript $p$ denotes the $p$-th penalty criterion, $\mathrm{B}^{\mathrm{p}}$ is the aspiration level of the $\mathrm{p}^{\text {th }}$ objective, and the symbol $\leq$ stands for approximately or nearly less than or equal to.

\section{Mathematical model}

Mathematical model of an unbalanced transportation problem with multiple fuzzy goals is stated as follows:

Find $x_{i j}, i=1,2, \ldots, m ; j=1,2, \ldots, n$ so as to satisfy the following

constraints and fuzzy goals:

$$
\sum_{j=1}^{n} x_{i j} \leq a_{i}, \quad i=1,2, \ldots, m
$$

$$
\begin{aligned}
& \sum_{i=1}^{m} x_{i j} \underset{\%}{\geq} b_{j}, \quad j=1,2, \ldots, n \\
& Z_{p}=\sum_{i=1}^{m} \sum_{j=1}^{n} c_{i j}^{p} x_{i j} \leq B^{p}, \quad p=1,2, \ldots, P(1) \\
& x_{i j} \geq 0, a_{i}>0, b_{j}>0, c_{i j}^{p} \geq 0 \text { for all } i, j \text { and } p \\
& \sum_{i=1}^{m} a_{i} \neq \sum_{j=1}^{n} b_{j}
\end{aligned}
$$

In an unbalanced problem, the total market requirements either exceed the total plant capacity (i.e., $\sum_{j=1}^{n} b_{j}>\sum_{i=1}^{m} a_{i}$ ) or less then the total plant capacity (i.e., $\sum_{j=1}^{n} b_{j}<\sum_{i=1}^{m} a_{i}$ ). In our unbalanced transportation model, we have considered (i.e., $\sum_{j=1}^{n} b_{j}>\sum_{i=1}^{m} a_{i}$ ).

Solution Procedure for the proposed model: The membership functions of the fuzzy demand goals are defined as:

$$
\mu_{A_{j}}(x)=\left\{\begin{array}{cc}
1 & \text { if } \sum_{i=1}^{m} x_{i j} \geq b_{j} \\
\left(\sum_{i=1}^{m} x_{i j}-b_{j}^{*}\right) /\left(b_{j}-b_{j}^{*}\right) & \text { if } b_{j}^{*}<\sum_{i=1}^{m} x_{i j}<b_{j} \\
0 & \text { if } \sum_{i=1}^{m} x_{i j} \triangleleft b_{j}^{*}
\end{array}\right.
$$

where $b_{j}^{*}(j=1,2, \ldots, n)$ is the lower tolerance limit of the $\mathrm{j}$-th demand goal.

The membership functions of the multiple fuzzy goals are defined as

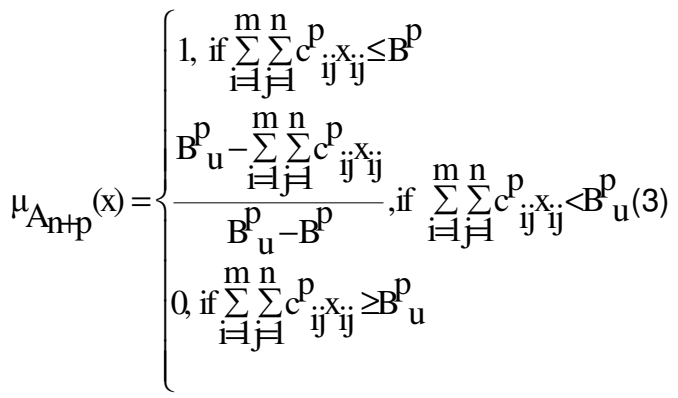

Where $B^{p}{ }_{u}(p=1,2, \ldots, P)$ is the upper tolerance limit of the $p$-th multiple fuzzy goal. Using maxmin operator, Problem (1) is equivalent to solving the following Linear programming.

$\operatorname{Max} \lambda$

$$
\begin{aligned}
& \lambda \leq \mu_{A_{j}}(x), \quad j=1,2, \ldots, n \\
& \lambda \leq \mu_{A_{n+p}}(x), p=1,2, \ldots, p
\end{aligned}
$$

Where 
$\boldsymbol{\lambda}=\operatorname{Min}\left[\frac{\sum_{i=1}^{m} x_{i j}-b_{j}^{*}}{\left(b_{j}-b_{j}^{*}\right)}, \frac{B_{u}^{p}-\sum_{i=1}^{m} \sum_{j=1}^{n} c^{p}{ }_{i j} x_{i j}}{B_{u}^{p}-B^{p}}\right]$

An equivalent linear programming model of the unbalanced transportation problem with multiple fuzzy goals (1) can be stated as follow:

$\operatorname{Max} \lambda$

Subject to

$$
\begin{aligned}
& \sum_{j=1}^{m} x_{i j} \leq a_{i}, \quad i=1,2, \ldots, m \\
& \lambda \leq \mu A_{j}(x), \quad j=1,2, \ldots, n \\
& \lambda \leq \mu A_{n+p}(x), \quad p=1,2, \ldots, n \\
& x_{i j} \geq 0 \text { for a } 11 \text { i a n d j } \\
& \lambda \geq 0
\end{aligned}
$$

Which is a linear programming model and can be solved by an appropriate linear programming algorithm.

\section{Interval weights with FGP}

We formulate the initial fuzzy goal-programming model of unbalanced multiobjective Transportation problem stated in (1), and then transform it into interval weights FGP model (i.e., a linear programming problem). The steps are as follows:

Step 1: Construct the membership function for the fuzzy demand goals and multiple fuzzy goals is defined as (2) and (3)

Step 2: Use the max-min operator

Step 3: Formulate a linear programming problem equivalent to problem (1). By using the max-min operator, the overall achievement function is defined as (4)

An equivalent linear programming model of the unbalanced transportation problem with multiple fuzzy goals (1) is defined as (5)

Step 4: The equivalent interval weights fuzzy goal programming model of the unbalanced Multiobjective transportation problem, stated in membership function of the demand goals and membership function of the multiple fuzzy goals. Let $\left(\mathrm{W}_{\mathrm{j}}, \mathrm{W}_{\mathrm{j}}^{*}\right)$ are the interval weights associated with the membership functions of demand goals $\mu_{\mathrm{Aj}}$, for $\mathrm{j}=1,2, \ldots, \mathrm{n}$ and $\left(\mathrm{W}_{\mathrm{n}+1}\right.$, $\left.W_{n+P}^{*}\right)$ is interval weight associated with the membership function of the multiple fuzzy goals. Let us denote the weighted membership function of demand goals as $\mu_{\mathrm{wj}}, \mathrm{J}=1,2, \ldots, \mathrm{n}$ is defined as follows:
$\mu_{w_{j}}=\left\{\begin{array}{cc}\frac{\mu_{A_{j}}-w_{j}}{w_{j}^{*}-w_{j}}, w_{j} \leq \mu_{A_{j}} \leq w^{*} & \text { otherwise } \\ 0, & \end{array}\right.$

or

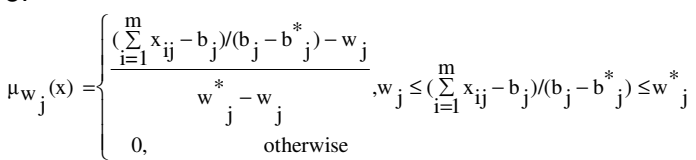

The weighted membership functions of multiple fuzzy goals $\mu_{w_{n+p}}$ can be defined as:

$\mu_{\mathrm{w}_{n+p}}(\mathrm{x})=\left\{\begin{array}{l}\mu_{\mathrm{A}_{n+p}-\mathrm{w}_{n+p}} \\ \mathrm{w}^{*}{ }_{\mathrm{n}+\mathrm{p}}-\mathrm{w}_{\mathrm{n}+\mathrm{p}} \\ 0, \text { otherwise }\end{array} w_{n+p} \leq \mu_{\mathrm{A}_{\mathrm{n}+\mathrm{p}}} \leq \mathrm{w}^{*}{ }_{\mathrm{n}+\mathrm{p}}(7)\right.$

which is equivalent to,

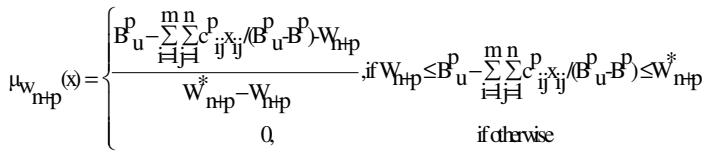

Thus the weighted structure with interval weights of the model (1) is formulated as follows:

$\operatorname{Max} \lambda$

Subject to

$$
\begin{aligned}
& \sum_{j=1}^{m} x_{i j} \leq a_{i}, \quad i=1,2, \ldots, m \\
& \lambda \leq w A_{j}(x), \quad j=1,2, \ldots, n \\
& \lambda \leq w A_{n+p}(x), \quad p=1,2, \ldots, P \\
& x_{i j} \geq 0 \text { for all i and } j \\
& \lambda \geq 0
\end{aligned}
$$

where,

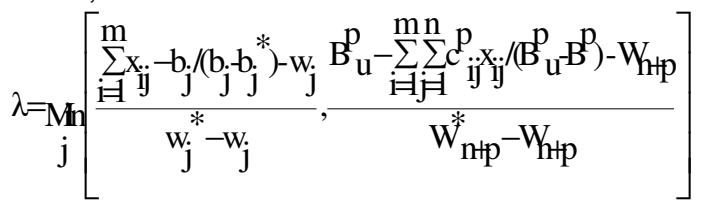

Which is linear programming problem can be solved by an appropriate linear programming algorithm.

\section{Numerical example}

A food grains supply company has three warehouses (sources) from where the processed food grains are supplied to four different demand points (destinations). The decision maker desires that the transportation cost and the total deterioration of goods should be around 210 dollars and 260 kilograms, respectively. The availabilities at the three sources are 8,10 , and 18 quintals, respectively. The requirements of the 
four different demand points are around 11, 5, 14 and 10 quintals, respectively. The transportation cost in dollars (i.e. $\mathrm{c}_{\mathrm{ij}}^{1}$,) per quintal from the $\mathrm{i}$-th warehouse to the j-th destination is given below in matrix $c^{1}$. The deterioration rate in kilograms (i.e., $\mathrm{c}_{\mathrm{ij}}^{2}$ ) per quintal for the product from the $\mathrm{i}$-th warehouse to the j-th destination is given below in the matrix $c^{2}$. Let us suppose that the Decision Maker (DM) wants to achieve at least 50 percent of the actual demand at each demand points. The DM is also interested to find out the amount of grains in quintals (i.e., $x_{i j}$ ) to be transported from the $i$-th warehouse to $j$-th destination so as to satisfy all his requirements.

The transportation cost matrix and the deterioration matrix are given as:

$$
\begin{aligned}
C^{1} & =\left[\begin{array}{cccc}
3 & 4 & 9 & 9 \\
3 & 11 & 5 & 6 \\
10 & 11 & 6 & 8
\end{array}\right] \\
C^{2} & =\left[\begin{array}{cccc}
6 & 6 & 5 & 6 \\
7 & 10 & 11 & 12 \\
8 & 4 & 7 & 9
\end{array}\right]
\end{aligned}
$$

Let us assume that, the upper tolerance limits of the transportation cost and the total deterioration of goods are 230 dollars and 260 kilograms, respectively. Thus, the problem can be modeled as follows :

Find $\quad \mathrm{x}_{\mathrm{ij}}, \quad \mathrm{i}=1,2,3 ; \mathrm{j}=1,2,3,4$

$$
\begin{aligned}
& \sum_{j=1}^{4} x_{1 j} \leq 8, \quad \sum_{j=1}^{4} x_{2 j} \leq 10, \quad \sum_{j=1}^{4} x_{3 j} \leq 18, \\
& \sum_{i=1}^{3} x_{i 1} \geq 11, \quad \sum_{i=1}^{3} x_{i 2} \geq 5, \quad \sum_{i=1}^{3} x_{i 3} \geq 14, \quad \sum_{i=1}^{3} x_{i 4} \geq 10
\end{aligned}
$$$$
z_{1}=\sum_{i=1}^{3} \sum_{j=1}^{4} c^{1} i j{ }^{x} i_{\%} 210
$$$$
z_{2}=\sum_{i=1}^{3} \sum_{j=1}^{4} c^{2} i j x i j \leq 240
$$$$
x_{i j} \geq 0, \text { for a } 11 \text { i and } j
$$

Where

$$
\begin{aligned}
\mathrm{z}_{1}= & 3 \mathrm{x}_{11}+4 \mathrm{x}_{12}+9 \mathrm{x}_{13}+9 \mathrm{x}_{14}+3 \mathrm{x}_{21}+11 \mathrm{x}_{22}+5 \mathrm{x}_{23} \\
& +6 \mathrm{x}_{24}+10 \mathrm{x}_{31}+11 \mathrm{x}_{32}+6 \mathrm{x}_{33}+8 \mathrm{x}_{34} \\
\mathrm{z}_{2} & =6 \mathrm{x}_{11}+6 \mathrm{x}_{12}+5 \mathrm{x}_{13}+6 \mathrm{x}_{14}+7 \mathrm{x}_{21}+10 \mathrm{x}_{22}+11 \mathrm{x}_{23} \\
& +12 \mathrm{x}_{24}+8 \mathrm{x}_{31}+4 \mathrm{x}_{32}+7 \mathrm{x}_{33}+3 \mathrm{x}_{34}
\end{aligned}
$$

The membership functions $\mu_{1}(x), \mu_{2}(x), \mu_{3}(x)$, and $\mu_{4}(x)$ of the demand goals, and the membership function $\mu_{5}(x)$, and $\mu_{6}(x)$, of the cost and deterioration goals, respectively, are defined as follows :

$$
\begin{aligned}
& \mu_{1}(x)=\left\{\begin{array}{cl}
1, & \text { if } x_{11}+x_{21}+x_{31} \geq 11 \\
x_{11}+x_{21}+x_{31}-5.5 & \text { if } 5.5<x_{11}+x_{21}+x_{31}<11 \\
11-5.5 & \text { if } x_{11}+x_{21}+x_{31} \leq 5.5
\end{array}\right. \\
& \mu_{2}(x)=\left\{\begin{array}{cl}
1, & \text { if } x_{12}+x_{22}+x_{32} \geq 5 \\
\frac{x_{12}+x_{22}+x_{32}-2.5}{5-2.5} & \text { if } 2.5<x_{12}+x_{22}+x_{32}<5 \\
0, & \text { if } x_{12}+x_{22}+x_{32} \leq 2.5
\end{array}\right. \\
& \mu_{3}(x)=\left\{\begin{array}{cl}
1, & \text { if } x_{13}+x_{23}+x_{33} \geq 14 \\
\frac{x_{13}+x_{23}+x_{33}-7}{14-7}, & \text { if } 7<x_{13}+x_{23}+x_{33}<14 \\
0, & \text { if } x_{13}+x_{23}+x_{33} \leq 7
\end{array}\right. \\
& \mu_{4}(x)=\left\{\begin{array}{cc}
1, & \text { if } x_{14}+x_{24}+x_{34} \geq 10 \\
\frac{x_{14}+x_{24}+x_{34}-5}{10-5}, & \text { if } 5<x_{14}+x_{24}+x_{34}<10 \\
0, & \text { if } x_{14}+x_{24}+x_{34} \leq 5
\end{array}\right. \\
& \mu_{5}(x)=\left\{\begin{array}{cc}
1, & \text { if } z_{1} \leq 210 \\
\frac{230-z_{1}}{230-210}, & \text { if } 210<z_{1}<230 \\
0, & \text { if } z_{1} \geq 230
\end{array}\right. \\
& \mu_{6}(x)=\left\{\begin{array}{cl}
1, & \text { if } z_{2} \leq 240 \\
\frac{260-z_{2}}{260-240}, & \text { if } 240<z_{2}<260(15) \\
0, & \text { if } z_{2} \geq 260
\end{array}\right.
\end{aligned}
$$

An equivalent linear programming of the problem (9) is formulated as follows:

Max $\lambda$

Subject to

$$
\begin{aligned}
& \sum_{j=1}^{4} x_{1 j} \leq 8, \quad \sum_{j=1}^{4} x_{2 j} \leq 10, \quad \sum_{j=1}^{4} x_{3 j} \leq 18 \\
& X_{11}+X_{21}+X_{31}-5.5 \lambda \geq 5.5 \\
& X_{12}+X_{22}+X_{32}-2.5 \lambda \geq 2.5 \\
& X_{13}+X_{23}+X_{33}-7 \lambda \geq 7 \\
& X_{14}+X_{24}+X_{3}-5 \lambda \geq 5 \\
& Z_{1}+20 \lambda \leq 230 \\
& Z_{2}+20 \lambda \leq 260 \\
& x_{i j} \geq 0, \text { for all } i \text { and } j \text { and } \lambda \geq 0
\end{aligned}
$$

Solution of the problem (16) obtained by using LINDO are presented as follows:

$$
\lambda=0.80
$$

$\mathrm{X}_{11}=0.0000, \mathrm{X}_{21}=7.7018, \mathrm{X}_{31}=2.1981$,

$X_{12}=4.0590, X_{22}=0.4409, X_{32}=0.0000$,

$X_{13}=0.0000, X_{23}=0.0000, X_{33}=12.6000$,

$X_{14}=3.9409, X_{24}=1.8572, X_{34}=3.2018$.

From the results, we observe the following points: Amount of food grains supplied from source $\mathrm{O}_{1}=$ 7.9999 quintals.

Amount of food grains supplied from source $\mathrm{O}_{2}=$ 9.9999 quintals. 
Amount of food grains supplied from source $\mathrm{O}_{3}=$ 17.9999 quintals

Demand fulfilled at destination $D_{1}=9.8999$ quintals.

Demand fulfilled at destination $\mathrm{D}_{2}=4.4999$ quintals.

Demand fulfilled at destination $D_{3}=12.6000$ quintals

Demand fulfilled at destination $\mathrm{D}_{4}=8.9999$ quintals.

Total demand fulfilled $=35.9997$ quintals.

Total supply $=35.9997$ quintals.

Transportation cost $=213.998$ dollars.

Total deterioration of $=243.9976$ kilograms .

We assign the following interval weights to the membership functions

$\mu_{\mathrm{w}_{1}}(\mathrm{x}), \mu_{\mathrm{w}_{2}}(\mathrm{x}), \mu_{\mathrm{w}_{3}}(\mathrm{x}), \mu_{\mathrm{w}_{4}}(\mathrm{x}), \mu_{\mathrm{w}_{5}}(\mathrm{x})$ and $\mu_{\mathrm{w}_{6}}(\mathrm{x})$, are $(0.0,1.0),(0.1,0.9),(0.2,0.8),(0.3,0.7)$, $(0.0,0.85),(0.1,0.85)$ respectively.

Now the weighted membership function for the demand and multiple goals are $\mu_{\mathrm{w}_{1}}(\mathrm{x}), \mu_{\mathrm{w}_{2}}(\mathrm{x}), \mu_{\mathrm{w}_{3}}(\mathrm{x}), \mu_{\mathrm{w}_{4}}(\mathrm{x}), \mu_{\mathrm{w}_{5}}(\mathrm{x})$ and $\mu_{\mathrm{w}_{6}}(\mathrm{x})$, respectively and are as given below:

$\mu_{\mathrm{w}_{1}}(\mathrm{x})=\left\{\begin{array}{c}\frac{\mathrm{x}_{11}+\mathrm{x}_{21}+\mathrm{x}_{31}-10.5}{11-5.5}-0 \\ 0, \begin{array}{c}1.0-0 \\ \text { if otherwise }\end{array}\end{array}\right.$, if $0 \leq \frac{\mathrm{x}_{11}+\mathrm{x}_{21}+\mathrm{x}_{31}-5.5}{11-5.5} \leq 1.0$

$\mu_{\mathrm{w}_{2}}(\mathrm{x})=\left\{\begin{array}{c}\frac{\mathrm{x}_{12}+\mathrm{x}_{22}+\mathrm{x}_{32}-2.5}{5-2.5}-0.1 \\ 0, \quad \begin{array}{c}0.9-1 \\ \text { if otherwise }\end{array}\end{array}\right.$, if $0.1 \leq \frac{\mathrm{x}_{12}+\mathrm{x}_{22}+\mathrm{x}_{32}-2.5}{5-2.5} \leq 0.9$

$\mu_{\mathrm{w}_{3}}(\mathrm{x})=\left\{\begin{array}{c}\frac{\frac{\mathrm{x}_{13}+\mathrm{x}_{23}+\mathrm{x}_{33}-7}{14-7}-0.2}{0.8-0.2}, \text { if otherwise }\end{array}\right.$, if $0.2 \leq \frac{\mathrm{x}_{13}+\mathrm{x}_{23}+\mathrm{x}_{33}-7}{14-7} \leq 0.8$

$\mu_{\mathrm{w} 4}(\mathrm{x})=\left\{\begin{array}{c}\frac{\mathrm{x}_{14}+\mathrm{x}_{24}+\mathrm{x}_{34}-5}{10-5}-0.3 \\ 0.7-0.3 \\ 0, \quad \text { if otherwise }\end{array}\right.$, if $0.3 \leq \frac{\mathrm{x}_{14}+\mathrm{x}_{24}+\mathrm{x}_{34}-5}{10-5} \leq 0.7$

$\mu_{\mathrm{w} 5}(\mathrm{x})=\left\{\begin{array}{l}\frac{230-\mathrm{z}_{1}}{230-210}-0.0 \\ \begin{array}{c}0.85-0.0 \\ 0, \text { if otherwise }\end{array}\end{array}\right.$

$\mu_{\mathrm{w}_{6}}(\mathrm{x})=\left\{\begin{array}{l}\frac{\frac{260-\mathrm{z}_{2}}{260-240}-0.1}{0.85-0.1}, \text { if } 0.1 \leq \frac{260-\mathrm{z}_{2}}{260-240} \leq 0.85 \\ 0, \text { if otherwise }\end{array}\right.$

An equivalent linear programming of the problem (9) is formulated as follows:

$\operatorname{Max} \lambda$

Subject to

$\sum_{j=1}^{4} x_{1 j} \leq 18, \quad \sum_{j=1}^{4} x_{2 j} \leq 20, \quad \sum_{j=1}^{4} x_{3 j} \leq 27$,

$\mathrm{X}_{11}+\mathrm{X}_{21}+\mathrm{X}_{31}-5.5 \lambda \geq 5.5$

$X_{12}+X_{22}+X_{32}-2 \lambda \geq 2.75$

$\mathrm{X}_{13}+\mathrm{X}_{23}+\mathrm{X}_{33}-4.2 \lambda \geq 8.4$ (23)
$\mathrm{X}_{14}+\mathrm{X}_{24}+\mathrm{X}_{3}-2 \lambda \geq 6.5$

$Z_{1}+17 \lambda \leq 230$

$\mathrm{Z}_{2}+15 \lambda \leq 258$

$x_{i j} \geq 0$ for all $i$ and $j$

$\lambda \geq 0$

Solutions of the problem (23) obtained by the LINDO software and are presented as follows:

$\lambda=0.9379$

$X_{11}=7.9999, X_{21}=3.0769, X_{31}=0.0000$,

$X_{12}=0.4181, X_{22}=0.0000, X_{32}=4.2077$,

$X_{13}=0.0000, X_{23}=6.9230, X_{33}=5.4163$,

$X_{14}=0.0000, X_{24}=0.0000, X_{34}=8.3759$.

From the results, we observe the following points: $\mathrm{O}_{1}=7.9999$ qunt., $\mathrm{O}_{2}=9.9999$ qunt., $\mathrm{O}_{3}=$ 17.9999 qunt, $D_{1}=10.6587 q u n t ., D_{2}=$ 4.6258qunt.,

$\mathrm{D}_{3}=12.3393 q u n t ., \mathrm{D}_{4}=8.3759$ qunt., Total demand fulfilled $=35.9997 q u n t$. Total supply $=$ 35.9997qunt.,

Transportation cost $=214.0532$ dollars .

Total deterioration of goods $=225.5633$ kilograms.

\section{FGP with Direct weights}

We formulate the initial fuzzy goal-programming model of unbalanced multiobjective transportation problem stated in (1), and then transform it into direct weights FGP model (i.e., a linear programming problem)

The steps are as follows:

Let $\mathrm{w}_{\mathrm{j}}$ 's for $\mathrm{j}=1,2, \ldots, \mathrm{n}$ are the weights, which are multiplied directly with the membership function of the demand and multiple goals $\mu_{\mathrm{A}_{\mathrm{j}}}$ and $\mu \mathrm{A}_{\mathrm{n}+\mathrm{p}}$ respectively and the resulting weighted membership function is denoted as:

$\mathrm{w}_{1} \mu_{1}(\mathrm{x}), \mathrm{w}_{2} \mu_{2}(\mathrm{x}), \mathrm{w}_{3} \mu_{3}(\mathrm{x}), \mathrm{w}_{4} \mu_{4}(\mathrm{x}), \mathrm{w}_{5} \mu_{5}(\mathrm{x})$, and $\mathrm{w}_{6} \mu_{6}(\mathrm{x})$, Thus the weighted structure with direct weights of the model (1), is formulated as follows:

$\operatorname{Max} \lambda$

Subject to

$$
\begin{aligned}
& \sum_{j=1}^{m} x_{i j} \leq a_{i}, i=1,2, \ldots, m \\
& \lambda \leq w A_{j}(x), \quad j=1,2, \ldots, n \\
& \lambda \leq w^{\mu} A_{n+p}(x), \quad p=1,2, \ldots, P \\
& x_{i j} \geq 0 \text { for all i and j } \\
& \lambda \geq 0
\end{aligned}
$$

Where,

$$
\lambda=\operatorname{Min}_{j}\left[\frac{w_{j}\left(\sum_{i=1}^{m} x_{i j}-b_{j}^{*}\right)}{\left(b_{j}-b_{j}^{*}\right)}, \frac{w_{n+p}\left(B_{u}^{p}-\sum_{i=1}^{m} \sum_{j=1}^{n} c^{p}{ }_{i j} x_{i j}\right)}{B_{u}^{p}-B^{p}}\right]
$$


We assign the following weights directly to the membership function

$\mu_{\mathrm{w}_{1}}(\mathrm{x}), \mu_{\mathrm{w}_{2}}(\mathrm{x}), \mu_{\mathrm{w}_{3}}(\mathrm{x}), \mu_{\mathrm{w}_{4}}(\mathrm{x}), \mu_{\mathrm{w}_{5}}(\mathrm{x})$ and $\mu_{\mathrm{w}_{6}}(\mathrm{x})$, are $0.1,0.2,0.3$,

$0.4,0.36$ and 0.357 respectively. Now the weighted membership for the demand and multiple goals are,

$\mu_{\mathrm{w}_{1}}(\mathrm{x}), \mu_{\mathrm{w}_{2}}(\mathrm{x}), \mu_{\mathrm{w}_{3}}(\mathrm{x}), \mu_{\mathrm{w}_{4}}(\mathrm{x}), \mu_{\mathrm{w}_{5}}(\mathrm{x})$ and $\mu_{\mathrm{w}_{6}}(\mathrm{x})$, respectively and are as follows:

$$
\begin{aligned}
& \mu_{\mathrm{w}_{1}}(\mathrm{x})=0.1\left(\frac{\mathrm{x}_{11}+\mathrm{x}_{21}+\mathrm{x}_{31}-5.5}{11-5.5}\right) \\
& \mu_{\mathrm{w}_{2}}(\mathrm{x})=0.2\left(\frac{\mathrm{x}_{12}+\mathrm{x}_{22}+\mathrm{x}_{32}-2.5}{5-2.5}\right) \\
& \mu_{\mathrm{w}_{3}}(\mathrm{x})=0.3\left(\frac{\mathrm{x}_{13}+\mathrm{x}_{23}+\mathrm{x}_{33}-7}{14-7}\right) \\
& \mu_{\mathrm{w}_{4}}(\mathrm{x})=0.4\left(\frac{\mathrm{x}_{14}+\mathrm{x}_{24}+\mathrm{x}_{34}-5}{10-5}\right) \\
& \mu_{\mathrm{w}_{5}}(\mathrm{x})=0.36\left(\frac{230-\mathrm{z}_{1}}{230-210}\right) \\
& \mu_{\mathrm{w}_{6}}(\mathrm{x})=0.357\left(\frac{260-\mathrm{z}_{2}}{260-240}\right)
\end{aligned}
$$

An equivalent linear programming of the problem (9) is formulated as follows:

$\operatorname{Max} \lambda$

Subject to

$\sum_{j=1}^{4} x_{1 j} \leq 8, \quad \sum_{j=1}^{4} x_{2 j} \leq 10, \quad \sum_{j=1}^{4} x_{3 j} \leq 18$,

$\mathrm{X}_{11}+\mathrm{X}_{21}+\mathrm{X}_{31}-5.5 \lambda \geq 5.5$

$X_{12}+X_{22}+X_{32}-12.5 \lambda \geq 2.5$

$\mathrm{X}_{13}+\mathrm{X}_{23}+\mathrm{X}_{33}-23.33 \lambda \geq 7$ (31)

$\mathrm{X}_{14}+\mathrm{X}_{24}+\mathrm{X}_{3}-12.5 \lambda \geq 5$

$Z_{1}+55.55 \lambda \leq 230$

$Z_{2}+56.022 \lambda \leq 260$

Solution of the problem (31) obtained by the simplex method are presented as follows:

$\lambda=0.2972$

$\mathrm{X}_{11}=4.8750, \mathrm{X}_{21}=2.2596, \mathrm{X}_{31}=0.0000$,

$X_{12}=3.1249, X_{22}=0.0000, X_{32}=3.0904$

$X_{13}=0.0000, X_{23}=7.7403, X_{33}=6.1941$,

$X_{14}=0.0000, X_{24}=0.0000, X_{34}=8.7154$.

From the results, we observe the following points: $\mathrm{O}_{1}=7.9999$ qunt., $\mathrm{O}_{2}=9.9999$ qunt., $\mathrm{O}_{3}=$ 17.9997qunt., $D_{1}=7.1346 q u n t$,

$\mathrm{D}_{2}=6.2153$ qunt., $\quad \mathrm{D}_{3}=13.9344$ qunt., $\quad \mathrm{D}_{4}=$ 8.7154qunt.,

Total demand fulfilled $=35.9997 q u n t$. Total supply $=35.9997 q u n t$.
Transportation cost $=213.4871$ dollars .

Total deterioration of goods $=230.8264$ kilograms.

\section{Conclusion}

In fuzzy goal programming formulation the aspiration levels of the fuzzy goals are fixed. The deviations from the goals in the fuzzy goal programming are under the control of the decision maker. In the numerical example (i) fuzzy formulations of the demand goals are within the reasonable limits. The transportation cost is 213.998 dollars and total deterioration of goods is 243.9976 Kilograms. (ii) The interval weights used in fuzzy goal programming model for unbalanced multiobjective transportation problem are also within the reasonable limits. The transportation cost is 214.0532 dollars and total deterioration of goods is 225.5633 Kilograms. (iii) the direct weights used in fuzzy goal programming model for unbalanced multiobjective transportation problems are also within the reasonable limits. The transportation cost is 213.4871 dollars and total deterioration of goods is 230.8264 Kilograms. Thus the present method is also suitable method for unbalanced transportation problem with multiple fuzzy goals.

\section{References}

[1] Bellman R. E. and Zadeh L. A. (1970) Management science 17, 141-164.

[2] Bit A. k., Biswal, M.P. and Alam S. S. (1993) Industrial Engineering Journal XXII, No. 6, 812.

[3] Hannan E. L. (1981) Fuzzy Sets and Systems.6, 235-248.

[4] Hannan E. L. (1981) Decision Sciences, 12, 522-531.

[5] Ignizio J. P. (1976) Goal programming and extensions, Heath Lexington Books, London.

[6] Ignizio J. P. (1882) Linear programming in single and multiple objective systems, Prentice-Hall, England cliffs NJ.

[7] Ignizio J. P. (1883) Computers and Operations Research, 10, 277-289.

[8] Kwak N. K., (1979) OMEGA 7, 367-370.

[9] Lee S. M. (1972) Goal programming for decision analysis, Auerbach, Philadelphia,.

[10] Lee S. M. and L. J. Moore. (1973) AlIE Transportation 5, 333-337

[11] Norseman K. (1980) Decision Science, 11, 325336.

[12] Romero C. (1886) European Journal of and Operations Research 25, 183-191.

[13] Singh V. N. and Kishore N. (1991) Industrial Engineering Journal XX, 16-22.

[14] Tiwari R.N., Dharmar S. and Rao J. R. (1986) Fuzzy Sets and Systems 19, 251-259.

[15] Tiwari R.N., Dharmar S. and Rao J. R. (1987) Fuzzy Sets and Systems 24, 27-34. 